\title{
Risk Neutral Option Pricing With Neither Dynamic Hedging nor Complete Markets, A Measure-Theoretic Proof
}

\author{
Nassim Nicholas Taleb*† \\ *Former Option Trader \\ ${ }^{\dagger}$ School of Engineering, NYU
}

\begin{abstract}
Proof that under simple assumptions, such as constraints of Put-Call Parity, the probability measure for the valuation of a European option has the mean of the risk-neutral one, under any general probability distribution, bypassing the Black-Scholes-Merton dynamic hedging argument, and without the requirement of complete markets. We show that the heuristics used by traders for centuries are both more robust and more rigorous than held in the economics literature.
\end{abstract}

\section{BACKGROUND}

Option valuations methodologies have been used by traders for centuries, in an effective way (Haug and Taleb, 2010). In addition, valuations by expectation of terminal payoff center the probability distribution around the "risk-neutral" forward, thanks to Put-Call Parity. The Black Scholes argument (Black and Scholes, 1973, Merton, 1973) is held to allow risk-neutral option pricing thanks to dynamic hedging. This is a puzzle, since: 1) Dynamic Hedging is not operationally feasible in financial markets owing to the dominance of portfolio changes resulting from jumps, 2) The dynamic hedging argument doesn't stand mathematically under fat tails, as it requires a "Black Scholes world" with many impossible assumptions, one of which requires finite quadratic variations, 3) We use the same Black-Scholes risk neutral arguments for the valuation of options on assets that do not allow dynamic hedging, 4) There are fundamental informational limits preventing the convergence of the stochastic integral, explained further down. ${ }^{1}$

There have been a couple of predecessors to the present thesis that Put-Call parity is sufficient constraint to enforce risk-neutrality, such as Derman and Taleb (2005), Haug and Taleb (2010), which were based on heuristic methods, robust though deemed hand-waving (Ruffino and Treussard, 2006). This paper uses a completely distribution-free, expectationbased approach and proves the risk-neutral argument without dynamic hedging, and without any distributional assumption, with solely two constraints: "horizontal", i.e. Put-Call Parity, and "vertical", i.e. the different valuations across strike prices deliver a probability measure (Dupire, 1994), which is shown to be unique. The only economic assumption made is that the forward is tradable by cash-and-carry style arbitrage - in the

\footnotetext{
${ }^{1}$ Further, in a case of scientific puzzle, the exact formula called "BlackScholes-Merton" was written down (and used) by Edward Thorp in a heuristic derivation by expectation that did not require dynamic hedging.
}

absence of such forward it is futile to discuss standard option pricing.

Aside from the cash and carry arbitrage, we make no assumption of market completeness. Options are not redundant securities and remain so. ${ }^{2}$

\section{PROOF}

Define $C\left(S_{t_{0}}, K, t\right)$ and $P\left(S_{t_{0}}, K, t\right)$ as European-style call and put with strike price $\mathrm{K}$, respectively, with expiration $t$, and $S_{0}$ as an underlying security at times $t_{0}, t \geq t_{0}$, and $S_{t}$ the possible value of the underlying security at time t.

Define $r=\int_{t_{0}}^{t} r_{s} \mathrm{~d} s$, the return of a risk-free money market fund and $\delta=\int_{t_{0}}^{t} \delta_{s} \mathrm{~d} s$ the payout of the asset (continuous dividend for a stock, interest for a currency).

We have the arbitrage forward price $F_{t}^{Q}$ :

$$
F_{t}^{Q}=S_{0} \frac{(1+r)^{\left(t-t_{0}\right)}}{(1+\delta)^{\left(t-t_{0}\right)}} \approx S_{0} e^{(r-\delta)^{\left(t-t_{0}\right)}}
$$

by arbitrage, see Keynes 1924 . We thus call $F_{t}^{Q}$ the future (or forward) price obtained by arbitrage, at the risk-neutral rate. Let $F_{t}^{P}$ be the future requiring a risk-associated "expected return" $m$, with expected forward price:

$$
F_{t}^{P}=S_{0}(1+m)^{\left(t-t_{0}\right)} \approx S_{0} e^{m\left(t-t_{0}\right)}
$$

Remark: By arbitrage, all tradable values of the forward price given $S_{t_{0}}$ need to be equal to $F_{t}^{Q}$.

"Tradable" here does not mean "traded", only subject to arbitrage replication by "cash and carry", that is, borrowing cash and owning the secutity yielding $d$ if the embedded forward return diverges from $r$.

Define $\Omega=[0, \infty)=A_{K} \cup A_{K}^{c}$ where $A_{K}=[0, K)$ and $A_{K}^{c}=[K, \infty)$.

Consider a class of standard (simplified) probability spaces $\left(\Omega, \mu_{i}\right)$ indexed by $i$, where $\mu_{i}$ is a probability measure satisfying $\int_{\Omega} \mathrm{d} \mu_{i}=1$.

We apply the measures $\mu_{1}$ and $\mu_{2}$ respectively for the call

\footnotetext{
${ }^{2}$ The famed Hakkanson paradox is as follows: if markets are complete and options are redudant, why would someone need them? If markets are incomplete, we may need options but how can we price them? This discussion may have provided a solution to the paradox: markets are incomplete and we can price options.
} 
Table I

COMPARISON

\begin{tabular}{|c|c|c|}
\hline & $\begin{array}{l}\text { Black-Scholes } \\
\text { Merton }\end{array}$ & Put-Call Parity \\
\hline Type & $\begin{array}{l}\text { Continuous } \\
\text { rebalancing. }\end{array}$ & $\begin{array}{l}\text { Interpolative } \\
\text { static hedge. }\end{array}$ \\
\hline \multirow[t]{3}{*}{$\begin{array}{l}\text { Market As- } \\
\text { sumptions }\end{array}$} & $\begin{array}{l}\text { 1) Continuous } \\
\text { Markets, no } \\
\text { gaps, no jumps. }\end{array}$ & $\begin{array}{lr}\text { 1) Gaps } \\
\text { and jumps } \\
\text { acceptable. } \\
\text { Continuous } \\
\text { Strikes, } \\
\begin{array}{l}\text { acceptable } \\
\text { number } \\
\text { strikes. }\end{array} \\
\end{array}$ \\
\hline & $\begin{array}{l}\text { 2) Ability to bor- } \\
\text { row and lend un- } \\
\text { derlying asset for } \\
\text { all dates. }\end{array}$ & $\begin{array}{l}\text { 2) Ability to } \\
\text { borrow and } \\
\text { lend underlying } \\
\text { asset for single } \\
\text { forward date. }\end{array}$ \\
\hline & $\begin{array}{l}\text { 3) No transaction } \\
\text { costs in trading } \\
\text { asset. }\end{array}$ & $\begin{array}{l}\text { 3) Low transac- } \\
\text { tion costs in trad- } \\
\text { ing options. }\end{array}$ \\
\hline $\begin{array}{l}\text { Probability } \\
\text { Distr }\end{array}$ & $\begin{array}{l}\text { Requires all mo- } \\
\text { ments to be finite. } \\
\text { Excludes slowly } \\
\text { varying distribu- } \\
\text { tions }\end{array}$ & $\begin{array}{l}\text { Requires finite } \\
1^{\text {st }} \text { moment } \\
\text { (infinite variance } \\
\text { is acceptable). }\end{array}$ \\
\hline $\begin{array}{l}\text { Market } \\
\text { Complete- } \\
\text { ness }\end{array}$ & $\begin{array}{l}\text { Achieved } \\
\text { through dynamic } \\
\text { completeness }\end{array}$ & $\begin{array}{l}\text { Not required (in } \\
\text { the traditional } \\
\text { sense) }\end{array}$ \\
\hline $\begin{array}{l}\text { Realism of } \\
\text { Assumptions }\end{array}$ & Low & High \\
\hline $\begin{array}{ll}\text { Fitness } & \text { to } \\
\text { Reality } & \end{array}$ & $\begin{array}{l}\text { Only used } \\
\text { after "fudging" } \\
\text { standard } \\
\text { deviations per } \\
\text { strike. }\end{array}$ & $\begin{array}{l}\text { Portmanteau, } \\
\text { adapted to reality }\end{array}$ \\
\hline
\end{tabular}

and put valuation by expectation of final payoff:

$$
C=\int_{\Omega} f_{C} \mathrm{~d} \mu_{1},
$$

and

$$
P=\int_{\Omega} f_{P} \mathrm{~d} \mu_{2},
$$

respectively, and where $f_{C}$ and $f_{P}$ are $\left(S_{t}-K\right)^{+}$and $(K-$ $\left.S_{t}\right)^{+}$respectively.

Theorem 1. The probability measures associated with the valuation by expectation of terminal payoff of puts and calls are equal, namely $\mu_{1}(z)=\mu_{2}(z)$ holds for all $z \in \Omega$.

Proof. For clarity, set $r$ and $\delta$ to 0 without a loss of generality. By Put-Call Parity Arbitrage, a positive holding of a call ("long") and negative one of a put ("short") replicates a tradable forward; because of $\mathrm{P} / \mathrm{L}$ variations, using positive sign for long and negative sign for short:

$$
C\left(S_{t_{0}}, K, t\right)-P\left(S_{t_{0}}, K, t\right)+K=F_{t}^{P}
$$

necessarily since $F_{t}^{P}$ is tradable.

Put-Call Parity holds for all strikes, so:

$$
C\left(S_{t_{0}}, K+\Delta K, t\right)-P\left(S_{t_{0}}, K+\Delta K, t\right)+K+\Delta K=F_{t}^{P}
$$

for all $K \in \Omega$

Now a Call spread in quantities $\frac{1}{\Delta K}$, expressed as

$$
C\left(S_{t_{0}}, K, t\right)-C\left(S_{t_{0}}, K+\Delta K, t\right),
$$

delivers $\$ 1$ if $S_{t}>K+\Delta K, 0$ if $S_{t}<K$, and the quantity times $S_{t}-K$ if $K \leq S_{t} \leq K+\Delta K$, that is between 0 and $\$ 1$. Likewise, consider the converse argument for a put, with $\Delta K<S_{t}$.

At the limit, for $\Delta K \rightarrow 0$

$$
\frac{\partial C\left(S_{t_{0}}, K, t\right)}{\partial K}=-\int_{A_{K}^{c}} \mathrm{~d} \mu_{1}
$$

by the same argument:

$$
\frac{\partial P\left(S_{t_{0}}, K, t\right)}{\partial K}=\int_{A_{K}} \mathrm{~d} \mu_{2}=1-\int_{A_{K}^{c}} \mathrm{~d} \mu_{2}
$$

Combining Equations 5 and 6, dividing by $\frac{1}{\Delta K}$ and taking $\Delta K \rightarrow 0$ :

$$
-\frac{\partial C\left(S_{t_{0}}, K, t\right)}{\partial K}+\frac{\partial P\left(S_{t_{0}}, K, t\right)}{\partial K}=1
$$

for all values of $K$, so

$$
\int_{A_{K}^{c}} \mathrm{~d} \mu_{1}=\int_{A_{K}^{c}} \mathrm{~d} \mu_{2}
$$

hence $\mu_{1}\left(A_{K}\right)=\mu_{2}\left(A_{K}\right)$ for all $K \in[0, \infty)$.

Theorem 2. Puts and calls are required, by static arbitrage, to be evaluated at same as risk-neutral measure $\mu_{Q}$ as the tradable forward.

Proof.

$$
F_{t}^{P}=\int_{\Omega} F_{t} \mathrm{~d} \mu_{Q}
$$


From Equation 5

$$
\int_{\Omega} f_{C}(K) \mathrm{d} \mu_{1}-\int_{\Omega} f_{P}(K) \mathrm{d} \mu_{1}=\int_{\Omega} F_{t} \mathrm{~d} \mu_{Q}-K
$$

Taking derivatives on both sides, and since $f_{C}-f_{P}=S_{0}+$ $K$, we get the Radon-Nikodym derivative:

$$
\frac{\mathrm{d} \mu_{Q}}{\mathrm{~d} \mu_{1}}=1
$$

for all values of $\mathrm{K}$.

\section{COMMENT}

We have replaced the complexity and intractability of dynamic hedging with a simple, more benign interpolation problem, and explained the performance of pre-Black-Scholes option operators using simple heuristics and rules.

Options can remain non-redundant and markets incomplete: we are just arguing here for risk-neutral pricing (at the level of the expectation of the probability measure), nothing more. But this is sufficient for us to use any probability distribution with finite first moment, which includes the Lognormal, which recovers Black Scholes.

A final comparison. In dynamic heding, missing a single hedge, or encountering a single gap (a tail event) can be disastrous - as we mentioned, it requires a series of assumptions beyond the mathematical, in addition to severe and highly unrealistic constraints on the mathematical. Under the class of fat tailed distributions, increasing the frequency of the hedges does not guarantee reduction of risk. Further, the standard dynamic hedging argument requires the exact specification of the risk-neutral stochastic process between $t_{0}$ and $t$, something econometrically unwieldy, and which is generally reverse engineered from the price of options, as an arbitrage-oriented interpolation tool rather than as a representation of the process.

Here, in our Put-Call Parity based methodology, our ability to track the risk neutral distribution is guaranteed by adding strike prices, and since probabilities add up to 1 , the degrees of freedom that the recovered measure $\mu_{Q}$ has in the gap area between a strike price $K$ and the next strike up, $K+\Delta K$, are severely reduced, since the measure in the interval is constrained by the difference $\int_{A_{K}}^{c} \mathrm{~d} \mu-\int_{A_{K+\Delta K}}^{c} \mathrm{~d} \mu$. In other words, no single gap between strikes can significantly affect the probability measure, even less the first moment, which is the exact opposite of dynamic hedging. In fact it is no different from standard kernel smoothing methods for statistical samples, but applied to the distribution across strikes. ${ }^{3}$

The assumption about the presence of strike prices constitutes a natural condition: conditional on having a practical discussion about options, options strikes need to exist. Further,

\footnotetext{
${ }^{3}$ For methods of interpolation of implied probability distribution between strikes, see Avellaneda et al.(1997).
}

as it is the experience of the author, market-makers can add over-the-counter strikes at will, should they need to do so.

\section{ACKNOWLEDGMENT}

Marco Avellaneda, Hélyette Geman, Raphael Douady, Gur Huberman.

\section{REFERENCES}

Avellaneda, M., Friedman, C., Holmes, R., \& Samperi, D. (1997). Calibrating volatility surfaces via relative-entropy minimization. Applied Mathematical Finance, 4(1), 37-64.

Black, F., Scholes, M. (1973). The pricing of options and corporate liabilities. Journal of Political Economy 81, 637654.

Derman, E. and Taleb, N. (2005). The illusions of dynamic replication. Quantitative Finance, 5(4):323-326.

Dupire, Bruno, 1994, Pricing with a smile, Risk 7, 18-20.

Haug, E. G. and Taleb, N. N. (2010) Option Traders use Heuristics, Never the Formula known as Black-ScholesMerton Formula, Journal of Economic Behavior and Organizations.

Keynes, J.M., 1924. A Tract on Monetary Reform. Reprinted in 2000. Prometheus Books, Amherst New York.

Merton, R.C., 1973. Theory of rational option pricing. Bell Journal of Economics and Management Science 4, 141-183.

Ruffino, D., \& Treussard, J. (2006). Derman and Taleb's "The illusions of dynamic replication": a comment. Quantitative Finance, 6(5), 365-367.

Thorp, E.O., 1973. A corrected derivation of the Black-Scholes option model. In: Presented at the CRSP proceedings in 1976. 